\title{
Direito, política e tradição: paralelos entre Edmund Burke e Schopenhauer
}

\author{
Law, politics, and tradition: parallels between Edmund Burke and \\ Schopenhauer
}

\section{Rogério Moreira Orrutea Filho*}

Resumo: Inicialmente examina-se a filosofia política de Schopenhauer tal como registrada no Mundo como vontade e representação. Neste ponto, há fortes diferenças em relação a Burke, em especial naquilo que diz respeito à finalidade que legitima o Estado. Porém, veremos que na obra Parerga e Paralipomena, Schopenhauer assume posições extremamente similares àquelas que Burke defendeu nas Reflexões sobre a revolução na França. Em razão da enorme semelhança entre suas concepções, concluímos que o pensamento político mais tardio de Schopenhauer acrescenta pouco àquele de Burke, embora sua filosofia forneça a fundamentação antropológica de que o pensamento burkeano necessita.

Palavras-chave: Razão; Tradição; Liberalismo; Conservadorismo

Abstract: Initially it is examined the schopenhauerian political philosophy as exposed in The world as will and representantion. At this point, there is strong differences with Burke, specially the concern about the ends which legitimate the State. However, in Parerga and Paralipomena, Schopenhauer assumes opinions extremely similar to those defended by Burke in Reflexions. Because of such resemblance, it is concluded that the Schopenhauer's late political thought adds not so much to Burke's political thought, although schopenhauerian philosophy provides the anthropological foundations which burkean thought needs.

Keywords: Reason; Tradition; Liberalism; Conservatism

\section{Introdução}

Sobre a filosofia política de Schopenhauer, os intérpretes Birnbacher e Küpper escrevem que

é fora de dúvida que sua abordagem contém, a princípio, posições liberais. Porém, este ponto de partida sofre um deslocamento - a partir do ano de 1848 - cada vez maior em favor do polo conservador ${ }^{1}$.

\footnotetext{
${ }^{1}$ BIRNBACHER; KÜPPER, Schopenhauer und die Wert der Freiheit, p. 93. Todas as traduções de trabalhos escritos em línguas estrangeiras aqui citados são de nossa inteira responsabilidade.
}

Doutorado em andamento em Filosofia, Universidade Estadual de Londrina, Londrina, PR. E-mail: rogeriomofilho@gmail.com ORCID: https://orcid.org/0000-0001-6756-9603 
Com base nisso, podemos distinguir ao menos duas fases no pensamento político de Schopenhauer: uma primeira, mais liberal, e uma segunda, mais conservadora. A fase liberal (que encontra acolhimento textual na obra $O$ mundo como vontade e representação e em Sobre o fundamento da moral) caracteriza-se pela ênfase sobre a justificação teórica dos direitos naturais, bem como a restrição do Estado ao papel de instrumento de proteção dos mesmos. Já na fase posterior, conservadora (delineada no significativo §127 do tomo II de Parerga e Paralipomena), Schopenhauer expressa uma preocupação maior com mecanismos de efetivação de direitos e conservação da ordem política. Pode-se dizer que seu pensamento político transita do aspecto deontológico, marcado pela formulação de argumentos cujo objeto é a determinação da vigência dos direitos naturais, para o aspecto fático, por onde se busca a determinação das condições empíricas de efetividade dos direitos naturais. Veremos que esta transição da vigência para a efetividade do direito opera-se por concessões cada vez maiores feitas por Schopenhauer à importância das tradições, e consequente crítica àquilo que ele chama, no $\$ 127$ de Parerga, de "direito abstrato".

É justamente neste ponto que podemos notar forte similaridade entre o pensamento político mais maduro de Schopenhauer e aquele do conservador Edmund Burke, que muito antes de Schopenhauer, em sua obra Reflexões sobre a revolução na França (de 1790), já havia elaborado uma forte crítica ao "direito abstrato" e a consequente defesa das tradições. $\mathrm{Na}$ verdade, nosso objetivo principal é o de demonstrar que, em filosofia política, Schopenhauer tornou-se, por assim dizer, um burkeano espontâneo, no sentido de adotar posições político-filosóficas similares ao ilustre crítico da Revolução Francesa, sem que, ao menos aparentemente, estivesse ciente disso. Se sua adesão não fora espontânea, mas consciente, então seu burkeanismo talvez tenha permanecido inconfessável ${ }^{2}$. Em um notável trabalho bastante recente e próximo ao nosso tema, Flamarion Ramos conclui que Schopenhauer "é uma referência para esta tradição que remonta a Burke [...] e um estudo sobre o pensamento conservador [...] seria tudo menos irrelevante" ${ }^{3}$. Concordamos inteiramente com esta provocação de F. Ramos. E, talvez, um possível caminho para a melhor compreensão do pensamento conservador e sua relação com a filosofia de Schopenhauer se dê justamente através de um estudo mais profundo exclusivamente dedicado ao paralelismo entre Schopenhauer e Burke.

Entretanto, sublinha-se aqui que foge inteiramente ao escopo deste trabalho qualquer investigação de caráter histórico que revele, a partir de exames minuciosos sobre

\footnotetext{
2 Aparentemente, Schopenhauer não menciona Burke na parte político-jurídica de sua obra. Até onde sabemos, ele cita Burke apenas na Crítica à filosofia kantiana (W I, p. 645) e no cap. 6 dos suplementos ao Mundo como vontade e representação (W II, cap. 6, p. 81). Nos dois casos, Schopenhauer tinha em vista apenas a obra Investigaçôes sobre o belo e o sublime, na qual Burke ocupou-se exclusivamente de questões estéticas.
}

${ }^{3}$ RAMOS, Pessimismo e política: conservadorismo e crítica social a partir de Schopenhauer, p. 51-52. 
documentos apócrifos como cartas e anotações, o tipo de relação pessoal que o indivíduo Schopenhauer sustentou referentemente ao pensamento de Burke (por exemplo, se Schopenhauer de fato leu as Reflexões; e se leu, em que época, e como se deu sua recepção pessoal às ideias mostradas naquela obra...). Nosso objetivo é filosófico e, enquanto tal, julgamos suficiente a tentativa de aproximar ou contrastar o pensamento de Burke e o de Schopenhauer a partir do exame e articulação dos conceitos expostos em suas respectivas obras.

Passemos agora à exposição dos principais conceitos que compõem o pensamento jurídico-político de ambos: direitos naturais, fundamentação do Estado, crítica ao direito abstrato, e função das tradições. Durante a exposição, realizaremos paralelismos entre suas respectivas abordagens e definições filosóficas.

\section{Direito naturais e fundamentação do Estado}

Um dos pontos principais da crítica de Burke direcionada à Revolução Francesa seria o de que esta estaria comprometida com a efetivação dos "direitos do homem", assim entendidos como todos aqueles direitos que o ser humano, pelo simples fato de sê-lo, já deveria ter à sua disposição. No mesmo período (século XVIII), também é utilizada a nomenclatura "direitos naturais". É de conhecimento geral que tais direitos seriam aqueles que independem, em sua validade, de condições culturais ou políticas; não seriam restritos às circunstâncias impostas pelo espaço e tempo, pois seriam universais. Exatamente por isso, estes direitos poderiam ser compreendidos por meio de um puro exercício racional. Porém, enunciar a relação intrínseca (mediante raciocínios ou intuições) que há entre a autorização jurídica de exercício de um dado direito e a simples condição de ser humano, não significa garantir que de fato este direito pode ser exercido. Por vezes, a realidade não oferece as condições de exercício de um direito. O próprio Burke não era contrário à noção de "direito natural” per se: "estou tão longe de negar em teoria os verdadeiros direitos dos homens quanto meu coração, de negá-los na prática"4.

Mas quais seriam, para Burke, estes "verdadeiros" direitos dos homens? Certamente, um deles seria a propriedade: “[...] propriedade privada, de que o Estado não é proprietário [...] mas somente guardião e regulador" ${ }^{5}$. Em outro trecho, ele escreve que "é à propriedade do cidadão, e não às exigências do credor do Estado, que é feito o primeiro e original voto da sociedade civil"6. Este trecho é bastante significativo. Se é à propriedade privada que se faz "o primeiro e original voto da sociedade civil”, isso significa que Burke, semelhante a Locke, toma a defesa da propriedade como a finalidade pela qual a sociedade

\footnotetext{
${ }^{4}$ BURKE, Reflexões sobre a revolução na França, p. 101.

${ }^{5}$ BURKE, Reflexões sobre a revolução na França, p. 160.

${ }^{6}$ BURKE, Reflexões sobre a revolução na França, p. 168.
} 
é formada. Tem-se então na conservação da propriedade um critério (embora não seja o único) pelo qual o indivíduo pode julgar a legitimidade do Estado. Afinal, mesmo em sua crítica à ação revolucionária dos franceses, Burke não excluiu a priori um direito à sedição:

É somente uma necessidade primeira e suprema, uma necessidade que não é escolhida, mas que escolhe, uma necessidade fundamental para a deliberação, que não admite discussão e não precisa de evidência, a única que pode justificar o recurso à anarquia ${ }^{7}$.

Em outras palavras, há elementos de um contratualismo no discurso burkeano, embora seja preciso ressaltar aqui que Burke era enfático sobre o tipo de contratualismo ao qual ele aderira:

A sociedade é de fato um contrato. Contratos secundários sobre objetos de interesse meramente ocasional podem ser dissolvidos à vontade - mas o Estado não deve ser nivelado a um acordo de parceria em um negócio de pimenta e café [...]. Deve ser visto com outra reverência, porque não é uma parceria de coisas pertinentes apenas à existência animal [...]. É uma parceria de todas as ciências; de todas as artes; de todas as virtudes e toda a perfeição. Como as finalidades de tal parceria não podem ser obtidas em muitas gerações, torna-se uma parceria não só entre aqueles que estão vivos, mas entre aqueles que estão vivos, aqueles que estão mortos, e aqueles que estão por nascer. Cada contrato de cada Estado em particular é apenas uma cláusula no grande contrato primordial da sociedade eterna ${ }^{8}$.

Portanto, o contratualismo de Burke não restringe a sociedade política à satisfação de necessidades circunstanciais. Se é um contrato, trata-se de um acordo que vincula "vivos, mortos, e não nascidos”. Com isso, o que Burke deseja sublinhar é a posição do Estado (que é apenas uma "cláusula" no "grande contrato" da "sociedade eterna") de promotor da satisfação de necessidades e aspirações muito mais perenes do que aquelas que ordinariamente constituem-se em objeto de acordos particulares. Em outras palavras, a sociedade só pode ser vista como convenção se entender-se com isso uma convenção feita para promover e conservar aquilo que não é convencional (a busca humana pelas ciências, artes, virtudes e perfeição). Isso significa que o rompimento de semelhante acordo, que tem por objeto coisas tão altivas e sagradas, deve ser proibido, se tal rompimento for voluntário. Somente o rompimento imposto por necessidade, e não escolhido por capricho, justifica-se. Portanto, o citado "recurso à anarquia”, admitido por Burke, não é exceção à regra que proíbe o rompimento voluntário, porque trata-se igualmente de uma "necessidade" que é "uma parte, também, daquela disposição moral e

\footnotetext{
${ }^{7}$ BURKE, Reflexôes sobre a revolução na França, p. 154.

${ }^{8}$ BURKE, Reflexões sobre a revolução na França, p. 154.
} 
física das coisas a que o homem deve ser obediente pelo consentimento ou pela força" 9 . Afinal, no trecho anteriormente transcrito Burke deixa claro que o "recurso à anarquia" se justifica apenas num contexto de uma "necessidade" que "não é escolhida", mas "que escolhe".

Em termos muito menos herméticos articula-se o contratualismo schopenhaueriano. O raciocínio de Schopenhauer é bastante simples: definidos os direitos naturais (que segundo Schopenhauer são a vida, liberdade e propriedade), deve-se assumir o Estado como um instrumento de preservação destes direitos. Por isso, Schopenhauer define o Estado como uma "instituição de proteção": proteção diante de ataques externos, proteção diante de ataques internos, e proteção contra o próprio protetor (W II, cap. 47, p. 696-697). Em forte contraste em relação a Burke, Schopenhauer não idealiza uma "sociedade eterna”, convencionada para a promoção de interesses espirituais de toda a humanidade. Certamente há também em Schopenhauer um interesse não convencional que fundamenta a convenção estatal, mas este interesse restringe-se à vontade de vida e ao consequente impulso de autopreservação.

De acordo com Birnbacher e Küpper ${ }^{10}$ há pelo menos duas classes principais de teorias que buscam esclarecer as razões da formação do Estado: um "otimista”, cujo modelo é Aristóteles, e que consiste no argumento de que o Estado funda-se sobre uma disposição natural do homem, por ser um zoon politikon, e, deve-se acrescentar, o Estado subsiste para a promoção de uma "vida feliz"11; e o "pessimista", centrado em Hobbes, que concebe o homem como um ser cuja natureza impele-o à guerra de todos contra todos. Nestes termos, ao prevalecer na espécie humana motivações como a vontade de competir, desconfiança mútua e desejo de glória pessoal (expostas por Hobbes, no capítulo XIII de Leviatã, como as três principais causas de disputa), convenciona-se o Estado como mecanismo de proteção. A partir destas explicações, é fácil concluir com Birnbacher e Küpper que Schopenhauer sustenta a segunda teoria. Burke, porém, tem muito mais em comum com Aristóteles ${ }^{12}$, com exceção do fato de que Burke concebe o Estado como proveniente de um acordo - e neste sentido seu discurso permanece bastante atrelado à retórica moderna. O elemento natural e não-convencional é atribuído por Burke ao objeto deste acordo: a satisfação da inclinação humana à realização conjunta das "artes”, "ciências”, "virtudes” e "perfeição".

\footnotetext{
${ }^{9}$ BURKE, Reflexões sobre a revolução na França, p. 154-155.

${ }^{10}$ BIRNBACHER; KÜPPER, Schopenhauer und die Wert der Freiheit, p. 86.

${ }^{11}$ ARISTÓTELES, Política, cap. 1, §8, p. 21.

${ }^{12}$ Comparemos o trecho de Burke aqui transcrito sobre a sociedade enquanto parceria entre vivos, mortos, e aqueles ainda estão por nascer, com este de Aristóteles, da Ética a Nicômaco, livro VIII, §IX: "A comunidade de Estado não tem em vista suprir às necessidades presentes, mas ao bem necessário ao longo de toda a vida" (ARISTÓTELES, Ética a Nicômaco, p. 188).
} 
É claro que alguém poderia argumentar aqui que Burke distingue-se de Aristóteles naquela particularidade apenas em suas articulações verbais; em conceito, Burke também conceberia o homem como zoon politikon, e, portanto, talvez seu contratualismo seja apenas aparente. Por outro lado, reforçando o valor conceitual de sua retórica contratual, deve-se sublinhar que Burke admite uma ruptura do acordo pelo qual forma-se o Estado, desde que esta ruptura seja motivada por uma necessidade "não escolhida", tão irresistível quanto o finalismo que dirige a vida humana, que é a busca conjunta pela excelência moral e intelectual. A possibilidade desta ruptura, isto é, o “recurso à anarquia”, parece não ser teoricamente concebida por Aristóteles, exatamente pela condição humana de zoon politikon.

O fato é que os pensamentos de Burke e de Schopenhauer (em sua fase libera) sobre as finalidades do Estado são bastante antagônicos. Tem-se aqui o contraste entre uma concepção comunitarista (ou, ao menos, muito próxima do comunitarismo) e uma concepção liberal de Estado $^{13}$. Schopenhauer era radicalmente contrário às tentativas políticas (e filosóficas) de atribuir ao Estado outras funções que não aquela de simples "proteção": "se alguém atribui ao Estado outro fim para além daquele de proteção aqui exposto, então pode-se facilmente colocar em risco o fim verdadeiro” (W II, cap. 47, p. 698). Em Sobre o fundamento da moral, ele é mais enfático sobre este ponto:

Alguns filosofastros alemães desta época venal quiseram torcê-lo [o Estado] numa instituição de moralidade, educação e edificação, no pano de fundo da qual espreita o alvo jesuítico de suprimir a liberdade pessoal e o desenvolvimento individual do singular para fazer dele uma mera engrenagem de um Estado chinês e de uma máquina religiosa. Este é,

\footnotetext{
${ }^{13} \mathrm{O}$ comunitarismo consiste, em suas linhas mais gerais, na afirmação de que a comunidade humana (e aqui incluo a figura do Estado) se forma em torno do objetivo de promover, em conjunto, certos valores morais fundamentais comuns a toda a comunidade. Isso se distingue de uma concepção liberal na medida em que esta última tende a tratar os valores como um assunto privado, destinando o Estado a desempenhar uma função meramente protetiva das liberdades individuais. Para uma compreensão deste contraste entre comunitarismo e liberalismo, recomenda-se a leitura do artigo Aristóteles e o sentido político da comunidade ante o liberalismo, de César Augusto Ramos. Reconhecemos que há alguma ousadia de nossa parte quando incluímos Burke entre os comunitaristas. No entanto, parece-nos no mínimo razoável notar uma forte semelhança, ao menos no que diz respeito à visão sustentada sobre as finalidades da vida em comum, na medida em que Burke concebe a atuação do Estado e da sociedade como um elemento necessário no processo de cultivo conjunto das virtudes e das ciências, e que semelhante objetivo não está na classe das coisas escolhidas ou convencionadas, mas na categoria daquelas coisas que, conforme fórmula do próprio Burke, são "necessárias", que "não são escolhidas", mas que "escolhem". Por outro lado, considerando o quanto a figura de Burke está atrelada ao conservadorismo, é de se questionar no que se distinguiriam o comunitarismo e o conservadorismo. Ambas as formas de pensamento têm certamente algo em comum, sobretudo se considerarmos a influência que Aristóteles desempenha sobre os representantes das duas correntes. Mas acreditamos que este tipo de exame merece um trabalho específico.
} 
porém, o caminho pelo qual outrora, chegou-se a inquisições, autos-de-fé e guerras de religião (E II, §17, p. 147-148).

Certamente essa crítica poderia ser dirigida à teoria de Burke sobre o Estado e a "sociedade eterna", que seriam "acordos" destinados a cumprir muito mais do que a simples proteção da vida, propriedade e liberdade dos indivíduos. Schopenhauer exige a restrição das funções do Estado à mera proteção dos direitos dos indivíduos porque ele associa o aumento de atribuições estatais à diminuição das liberdades individuais. E é plenamente razoável admitir que um Estado promotor da excelência moral, ou da "perfeição" humana, corre o risco de engajar-se em incursões totalitárias. Porém, a concepção liberal também pode sofrer críticas. Nas palavras de McAllister,

a tendência liberal de transformar todas as questões de grande importância em preocupações privadas tem o efeito de fazer ruir a fundação espiritual de uma verdadeira comunidade [...]. Elas [as sociedades liberais] surgem como resposta a um consenso humano do tipo mais insignificante; no mais extremo dos casos, os membros de uma sociedade liberal só seriam capazes de concordar a respeito do mal maior (conforme representado pelo summum malum de Hobbes) ${ }^{14}$.

Sem um interesse comum para além do simples desejo de proteger-se de seu vizinho, sem uma espécie de "vínculo ontológico"15 que preexiste ao contrato, e que é condição de formação do mesmo, é impossível qualquer acordo entre os homens. O paradoxo da sociedade liberal seria a produção de indivíduos tão livres e independentes entre si, porque destituídos de uma "ontologia compartilhada”, a ponto de impossibilitar a própria comunicação entre eles. E, como lembra-nos McAllister, "em uma democracia, a comunicação é essencial”" ${ }^{6}$. Portanto, o excesso de pluralismo axiológico e a falta de consenso sobre bens supremos e inegociáveis para além daquele da própria liberdade individual minaria qualquer chance de acordos, afinal de contas, contra negantem principia non est disputandum ("não há de se discutir com aquele que não compartilha dos mesmos princípios” ${ }^{17}$.

\footnotetext{
${ }^{14}$ McALLISTER, Revolta contra a modernidade, p. 263.

${ }^{15}$ McALLISTER, Revolta contra a modernidade, p. 187.

${ }^{16}$ McALLISTER, Revolta contra a modernidade, p. 265.

${ }^{17}$ Aqui pode-se ensaiar um outro argumento que reforça a crítica ao liberalismo: este, aplicado aos debates, levou-nos a desqualificar a priori qualquer disputa intelectual sobre as questões mais sérias da vida (Deus, felicidade, finalidade e sacralidade da vida humana, alma, beleza, etc.), como discussões sobre posições pessoais, objetivamente incomunicáveis. Todos os grandes problemas são rebaixados ao nível de opiniões ou questões de gosto pessoal (exceto, é claro, o axioma que atesta o valor da liberdade individual). Neste sentido, talvez a fenomenologia de Husserl possa ser considerada como um projeto filosófico profundamente antiliberal, uma vez que busca resgatar a metafísica como uma ciência objetivamente comunicável (cf. HUSSERL, A crise das ciências europeias e a fenomenologia transcendental, p. 5 e ss.). Eis, portanto, o outro
} 


\section{Da "pura doutrina do direito" para a "arte da política”; críticas ao "direito abstrato"}

A teoria de Schopenhauer sobre os direitos naturais e formação do Estado, até aqui reconstruída, baseia-se em sua exposição na obra $O$ mundo como vontade e representação, em especial, no $\$ 62$ do primeiro tomo e no cap. 47 do segundo tomo. Porém, em seu trabalho posterior, a reunião de ensaios Parerga e Paralipomena (de 1850), mais especificamente no $\$ 127$ do segundo tomo, Schopenhauer apresenta uma visão complementar à sua teoria dos direitos naturais. Na verdade, percebe-se um deslocamento do discurso schopenhaueriano, antes predominantemente focado naquilo que ele próprio chamou de "pura doutrina do direito", doutrina esta consistente em determinar "a natureza e limites do que é justo e injusto” (W I, §62, p. 443), enquanto que no $\$ 127$ dos Parerga nota-se uma forte preocupação com a "arte da política” (Staatskunst). O objeto da “arte da política” não é a simples determinação do significado moral intrínseco às ações humanas, mas a relação entre direito e força (Gewalt):

O direito em si mesmo é impotente: pela natureza prevalece a força. Trazer essa para o lado do direito, de modo que por meio da força o direito prevaleça, este é o problema da arte da política (P II, §127, p. 271).

Portanto, a missão da arte política é a de transferir força ao direito para que este “prevaleça”. Em poucas palavras, a arte da política ocupa-se da questão da efetividade do direito, vale dizer, da eficácia ou capacidade de produzir efeitos na vida social. Diferentemente, a "pura doutrina do direito" ocupa-se de sua vigência ${ }^{18}$.

paradoxo do liberalismo: sob a escusa de tudo permitir (com exceção daquilo que interfere no campo de ação livre e individual alheia), ele anula a priori as chances de qualquer debate sério sobre os problemas mais sérios. Por outro lado, em favor do liberalismo pesa a simplicidade e evidência do argumento em sua defesa: a experiência demonstra que reclames por algo como um "vínculo ontológico" comum podem acabar por fundamentar, ainda que talvez apenas demagogicamente, a intromissão arbitrária dos poderes públicos sobre a esfera privada. E este é um argumento de peso considerável, sobretudo se considerarmos, como Schopenhauer, que a simplicidade é o sinal da verdade (E, §8, p. 75).

${ }^{18}$ Os termos eficácia e vigência não são empregados por Schopenhauer de modo claro, e ele muito menos realiza uma distinção rígida entre as duas coisas. Empregamos aqui estas expressões com alguma base na Teoria Pura de Direito de Hans Kelsen. Segundo o jurista austríaco, a vigência é o modo particular de existência de uma norma jurídica, e refere-se ao simples fato de a mesma impor uma regra ou comando. Se este comando produzirá efeitos, isto é, se ele será eficaz e de fato capaz de vincular o comportamento dos indivíduos aos quais o comando é endereçado, esta é uma outra questão, porque refere-se a um fato da ordem do Ser. As normas jurídicas, diferentemente, articulam-se na esfera do Dever-ser. A validade da norma localiza-se nesta tensão entre dever-ser e ser, isto é, ela não pode ser completamente eficaz, pois do contrário tornar-se-ia supérflua; mas se for totalmente destituída de eficácia, então cai em desuso, e com isso perde sua validade. Um certo nível de aplicação à realidade, mas também de contraposição à mesma é igualmente exigível como condição de validade da norma jurídica. Logo, a eficácia não se identifica com a validade do direito, mas nem por isso deixa de ser uma condição de validade do mesmo (cf. KELSEN, Teoria pura do direito, p. 235 e ss.). Por isso escreve Kelsen: "o direito não pode existir sem força, mas [...] não se identifica 
Por isso Schopenhauer escreve (W II, cap. 47, p. 696): “aqueles que, como Spinoza, negam que fora do Estado há um direito, confundem os meios de fazer o direito valer [geltend zu machen], com o direito" (o destaque é nosso). Em Schopenhauer haveria aquilo que poderíamos aqui chamar de direito em si (ou, para adequar-se melhor aos termos que utilizamos há pouco: o direito natural em seu estado de mera vigência, independente da eficácia), de um lado, e as condições que incorporam validade ao direito em si, do outro. Segundo Schopenhauer, esta condição é o Estado, pois só o Estado pode incorporar eficácia ou, o que é o mesmo, a força socialmente vinculante ao direito. Mas no §127 dos Parerga, Schopenhauer aprofunda esta análise sobre as condições fáticas de efetivação do direito, e é neste contexto em que ele realiza seu ataque àquilo que chamou de "direito abstrato", que é nada mais do que o direito natural, objeto de consideração da "pura doutrina do direito". Mais precisamente, a expressão "direito abstrato" é agora utilizada retoricamente num contexto de crítica às tentativas de aplicar diretamente o puro direito natural (o "direito em si”) à realidade. Quando os direitos naturais deixam de ser conteúdo de simples consideração teórica, e são postos na condição de objeto de real atuação política, eles se degeneram em “direitos abstratos", inadequados ao homem real: “a constituição de um Estado, na qual se incorporasse apenas o direito abstrato, seria uma excelente coisa para outros seres diferentes dos homens” (P II, §127, p. 274). Considerando a natureza dos seres humanos - "altamente egoístas, injustos, desrespeitosos, mentirosos, e até cruéis” (P II, §127, p. 274) -, o direito em si, para produzir efeitos na realidade, precisa misturar-se a elementos que, a princípio, são-lhe estranhos. Para explicar este ponto, Schopenhauer recorre à analogia entre direito e substâncias químicas:

Em geral, deve-se até mesmo admitir a hipótese de que o direito é de uma qualidade análoga à de certas substâncias químicas, as quais não se deixam expor quando puras e isoladas, mas apenas com uma pequena mistura, que lhes serve de sustentáculo, ou que lhes fornece a necessária consistência, tais como flúor, e mesmo álcool, ácido cianídrico, etc.; de modo que também o direito, se ele deve abrir caminho no mundo efetivo e até mesmo dominar, precisa necessariamente de uma pequena adição de arbítrio e força, para que assim - apesar de sua própria natureza apenas ideal e, por isso, etérea - possa efetivar-se e existir neste mundo real e material, sem evaporar e por isso voar para o céu, como ocorre em Hesíodo (P II, §127, p. 273-274).

com ela” (Teoria pura do direito, p. 238). Evidentemente, Kelsen era um positivista que não levava em conta os direitos naturais, mas apenas o direito positivo. Por isso, o uso que fazemos aqui destes conceitos kelsenianos é por analogia. Direitos naturais seriam analogamente vigentes, no sentido de estarem igualmente presentes em nossa consciência moral, independentemente de sua eficácia. 
Como exemplos de "adição de arbítrio e força", Schopenhauer cita certas disposições ou instituições jurídicas e sociais que encontram seu fundamento em elementos acidentais, localizados na história e cultura e que são responsáveis pela sustentação do poder e autoridade política, tais como "privilégios hereditários" e "religião estatal”. Schopenhauer admite que privilégios e a fixação de uma religião estatal não podem ser justificados pelo direito natural. Ele admite que nosso bom senso prefere a “investigação racional” à "religião nacional”, e que nossa razão nos diz que temos o direito originário de dizer a qualquer um “o que você é, eu sou também!” (P II, §127, p. 272). Mas do ponto de vista da "arte política”, que tem por missão descobrir os meios pelos quais é possível atribuir eficácia ao direito, tais regras seriam politicamente necessárias, pois assim supõe Schopenhauer - sem hierarquia não haveria um soberano, e sem soberano, não haveria ordem jurídica. Além disso, ao incluir a "religião estatal" na categoria de imposições jurídicas artificiais (mas politicamente necessárias), Schopenhauer parece pressupor a importância de existir algum consenso entre os súditos em torno de certos valores fundamentais. Afinal, qual seria o interesse do ateu e pessimista Schopenhauer na ideia de uma religião estatal, senão enquanto condição de instrumento de garantia da ordem? Vê-se, portanto, que o Estado adquire maiores atribuições ou funções no §127 de Parerga, para além da definição contida no Mundo como vontade e representação (e em Sobre o fundamento da moral) que qualifica-o exclusivamente como uma simples “instituição de proteção”. Segundo Münkler, foi após presenciar as revoluções de 1848 que o pessimismo de Schopenhauer passou a ser direcionado muito mais aos "protegidos" do que ao "protetor"19. Se esta hipótese histórica está correta ou não, o fato é que ocorre, em Schopenhauer, um aparente abandono daquele seu liberalismo em favor daquilo que poderíamos aqui qualificar como um paradoxal comunitarismo cético, pois motivado não pela crença no destino transcendente e conjunto da espécie humana, mas pelo temor e até descrença moral em relação às potências humanas quando destituídas de restrições religiosas.

Em suma, esta etapa mais madura do pensamento político de Schopenhauer (talvez formulada após as revoluções de 1848) caracteriza-se pela inclusão de três novas concepções teóricas: a ideia de uma “arte da política”, a crítica ao “direito abstrato”, e a exigência de se misturar o direito em si a regras artificiais, como condição de sua efetivação. Há ainda uma quarta, que é um inédito enaltecimento das tradições (e que será abordada mais adiante). Veremos que aquelas três concepções já haviam sido exploradas por Edmund Burke nas Reflexões sobre a Revolução na França. Muito similar à "arte política” schopenhaueriana e suas atribuições, Burke definia a função da "razão política" nestes termos:

${ }^{19}$ MÜNKLER, Ein janusköpfiger Konservatismus: Arthur Schopenhauers politische Idee, p. 221. 
A razão política é um princípio calculista: adiciona, subtrai, multiplica e divide moralmente - e não metafisicamente ou matematicamente verdadeiros valores morais. Dependendo desses teóricos [os defensores dos direitos abstratos], o direito das pessoas seria quase sempre sofisticamente confundido com o seu poder. [...] mas até que poder e direito sejam iguais, todo esse conjunto não tem nenhum direito incompatível com a virtude, e especialmente com a primeira de todas as virtudes, a prudência. Os homens não têm direito ao que não é razoável [... ${ }^{20}$.

Um direito, por si só, não é poder. O poder é um elemento político, e é pela política que deve ser decidida as condições de exequibilidade de um direito, pois poder é a capacidade fática de executar alguma coisa. A decisão quanto a estas condições depende de cálculos fornecidos pela "razão política”. Não devemos confundir essa "razão política” que calcula com alguma máxima utilitarista ${ }^{21}$. O objeto de cálculo aqui são as circunstâncias que constituem as condições de efetivação de um direito. A “razão política” consiste precisamente no exame destas circunstâncias, e é por isso que "razão política" e a virtude da prudência ("a primeira de todas as virtudes”), a phronesis aristotélica ${ }^{22}$, são indissociáveis. Sem a compreensão das circunstâncias, isto é, se são ignoradas as condições fáticas de exequibilidade de um direito, este se degrada em mera abstração ${ }^{23}$.

\footnotetext{
${ }^{20}$ BURKE, Reflexões sobre a revolução na França, p. 107.

${ }^{21}$ Apesar da retórica de Burke no trecho citado, seu pensamento político se desenvolve em oposição ao utilitarismo. Por isso escreve Russell Kirk em um dos trechos nos quais ele contrasta Burke e Bentham: "[Para Bentham] O objetivo da sociedade é o maior bem do maior número: Burke disse a mesma coisa, mas Burke queria com isso significar algo muito, muito diferente. O fundador do conservadorismo havia entendido a complexidade dos interesses humanos e a sutileza do Bem. O maior bem da maioria dos homens não reside na igualdade política, declarou Burke, ou na sua liberação de preconceitos e prescrições, ou na obsessão com questões econômicas. O seu maior bem, disse Burke, emana de sua conformidade à providencial ordem do universo: na piedade, no dever, e no amor duradouro. Mas Bentham deixou desdenhosamente de lado o mundo burkeano de espírito e imaginação" (KIRK, The conservative mind, p. 116). Portanto, a diferença entre Burke e Bentham é de ordem fundamental, pois a própria concepção de Bem é completamente diferente no pensamento filosófico de cada um. E é neste ponto que se percebe que, embora desdenhasse de metafísicos, Burke permaneceu profundamente metafísico relativamente à sua concepção de Bem. Portanto, não só a noção de “direitos naturais”, mas também a própria “metafísica” possui forte ambivalência no contexto do pensamento burkeano.

${ }^{22}$ Neste sentido, ver os parágrafos VI e VII do livro VI de Ética a Nicômaco: “A sensatez [phronesis] não abre apenas para coisas gerais, mas deve reconhecer as situações particulares e singulares em que de cada vez nos encontramos, porque a sensatez inere na dimensão da ação humana e a ação humana é a respeito das situações particulares em que cada vez nos encontramos. [...] A perícia política e a sensatez são uma e a mesma disposição" (ARISTÓTELES, Ética a Nicômaco, p. 136-137).

${ }^{23} \mathrm{E}$ aqui convém parafrasear aquelas amargas palavras de Hannah Arendt: o mundo não vê nada de sagrado na abstrata nudez de ser unicamente humano (ARENDT, Origens do totalitarismo, p. 408). Arendt compreendeu muito bem que cartas jurídicas que contêm uma longa lista de "direitos humanos" evidentes e
} 
Nisto consiste a possibilidade de conciliação entre o jurídico e o político, duas dimensões da vida social que permanecem em si bastante distintas. O primeiro consiste no estabelecimento de máximas e princípios; o segundo, no exame pormenorizado das particularidades. O âmbito político, sem o jurídico, pode facilmente conduzir-nos ao comportamento maquiavélico; e a dimensão jurídica, dissociada da política, é incapaz de efetivar-se. Apesar de distintos, ambos permanecem em uma irresolúvel relação tensional, onde afirmam suas respectivas diferenças ao mesmo tempo em que estabelecem acordos mútuos. A relação tensional entre a política e o direito é também uma relação tensional entre o particular e o universal. Este ponto não é explícito em Burke, mas pode sê-lo a partir de Schopenhauer, quando este distingue, no cap. 47 do Mundo como vontade $e$ representação, o direito (em nossas próprias palavras, o "direito em si") dos meios de efetivação do mesmo. A determinação do direito em si é objeto da "pura doutrina do direito"; a determinação dos meios fáticos de sua realização é assunto da "arte da política” (Schopenhauer) ou "razão política” (Burke). Neste último caso, a instância cognitiva não é a sophia dos teóricos, mas a phronesis dos homens práticos.

Esta relação tensional e complementar entre política e direito pode ser extraída daquilo que decidimos chamar, em Burke, de "metáfora da refração":

Estes direitos metafísicos [e aqui Burke está se referindo aos direitos abstratos] que entram na vida comum, como raios de luz penetrando em um meio denso, são refratados pelas leis da natureza de sua linha reta. De fato, na bruta e complicada massa de paixões e preocupações humanas, os direitos primitivos dos homens passam por uma tal variedade de refrações e reflexões que se torna absurdo falar deles como se continuassem na simplicidade de sua condição original ${ }^{24}$.

Deve-se notar o quanto a analogia da substância química formulada por Schopenhauer parece-se com esta metáfora da refração, de Burke. Nos dois casos, insistese sobre a impossibilidade de se aplicar o direito em seu estado puro, embora não se negue que tal direito exista, ou melhor, que seja vigente. Mas ainda que vigente (pois todos teríamos consciência dos nossos direitos naturais), sua validade é ameaçada pela ausência de efetividade. Desta forma, ele deve sofrer uma "refração" (Burke), ou uma "mistura" com elementos heterogêneos (Schopenhauer). De qualquer forma, a mensagem é esta: a realidade não oferece condições fáticas de acomodação ao direito natural em seu estado puro, e, por isso, adaptações precisam ser feitas.

universais, mas que são desacompanhados das condições reais de efetivação dos mesmos, não passam de poesia jurídica, flatus vocis.

${ }^{24}$ BURKE, Reflexões sobre a revolução na França, p. 105. 
Julgamos esta metáfora da refração extremamente significativa, porque nela parecenos estar contida a essência do pensamento filosófico e político de Burke relativamente à problemática dos direitos naturais. Ela demonstra que, por um lado, Burke, tal como Schopenhauer, não nega a vigência de direitos naturais universais (isto é, "metafísicos”), mas, por outro, não deixa de assumir que a efetivação destes direitos pode ser comparada a refrações que os raios de luz sofrem na natureza. Portanto, a essência de tais direitos é sempre a mesma, mas sua forma de aplicabilidade pode variar. Um mesmo direito natural pode sofrer maiores ou menores restrições em sua execução, a depender de fatores impostos pela realidade e que só podem ser bem compreendidos pela "razão política".

Quanto ao “direito abstrato”, sua expressão já era usada em sentido pejorativo por Burke, muito antes de Schopenhauer:

Qual é a utilidade de discutir o direito abstrato de um homem a alimentos ou medicamentos? A questão é sobre o método de adquiri-los e administrálos. Nessa deliberação, eu sempre aconselho a pedir a ajuda do agricultor e do médico em vez do professor de metafísica ${ }^{25}$.

Segundo Ivone Moreira, “o que Burke designa por abstração, e aquilo que reprova, é o conceito depurado das qualificações particulares, não a apreensão de uma essência universal”"26. Portanto, o "direito abstrato" seria aquele desvinculado das condições particulares de sua efetiva aplicação. Embora os direitos naturais possam reclamar, na própria obra de Burke, uma "essência universal” e inegável (o que fica evidente em seus discursos de condenação a fatos decorrentes da colonização inglesa na Índia), no entanto, quando dissociados das condições materiais, históricas e culturais de sua aplicação, eles se convertem em um simples flatus vocis, em "direito abstrato". Exatamente o mesmo pode ser dito sobre o posicionamento que Schopenhauer assume em relação ao direito abstrato, no $\$ 127$ de Parerga e Paralipomena.

\section{Enaltecimento das tradições e rejeição ao intelectualismo político}

Ao direito abstrato, Burke contrapõe o direito tradicional, nomenclatura que escolhemos aqui para nos referir à prescription, definida por Russell Kirk como "o direito costumeiro que se desenvolve a partir de convenções e acordos de muitas gerações sucessivas" ${ }^{27}$. Trata-se, consequentemente, do conjunto de normas jurídicas que nascem e se solidificam a partir de costumes reiterados ao longo de gerações; isto é, são tradições. Consequentemente, o direito tradicional (prescription) teria como prerrogativa a seu favor

\footnotetext{
${ }^{25}$ BURKE, Reflexões sobre a revolução na França, p. 104.

${ }^{26}$ MOREIRA, A filosofia politica de Edmund Burke, p. 224.

${ }^{27}$ KIRK, The conservative mind, p. 42.
} 
justamente aquilo que falta ao direito abstrato: ele recebeu seu aval da experiência de incontáveis gerações e, por isso, fora suficientemente testado.

Obviamente, sua permanência ${ }^{28}$ não é prova de sua perfeição; mas é prova de sua razoabilidade moral e de sua eficácia política, isto é, sua capacidade de ordenar a sociedade e de conservar os interesses dos cidadãos sob sua proteção. Em contraste, à "perfeição" dos direitos abstratos, corresponde, na mesma proporção, o seu "defeito prático" 29.

Também Schopenhauer acabou por reconhecer a importância das tradições no processo político de efetivação dos direitos naturais. Ainda que em seus trabalhos anteriores ele tenha restringido sua filosofia à investigação do universalmente justo e injusto, no entanto percebe-se que, no já citado \$127 de Parerga e Paralipomena, Schopenhauer faz concessões às tradições, o que é coerente com o propósito filosófico de uma "arte da política”:

Os ingleses exibem seu grande entendimento também pelo fato de que conservam fixas e sagradas suas antigas instituições, costumes e usos, sob o risco de levar esta tenacidade longe demais e até mesmo cair no ridículo; exatamente porque aquelas coisas não foram arquitetadas por uma cabeça ociosa, mas desenvolveram-se gradualmente a partir do poder das circunstâncias e da sabedoria da própria vida, e por isso, são adequadas a eles enquanto nação (P II, §127, p. 279).

O ponto fundamental do argumento de Schopenhauer em favor das tradições consiste na atribuição, a estas últimas, de uma sabedoria superior aos conceitos criados por “cabeças ociosas”. Nas tradições, está contida uma "sabedoria da própria vida”. Além disso, os costumes tradicionais não são arbitrários, mas resultado de uma reação coletiva e gradual ao "poder das circunstâncias". As tradições seriam, então, o repositório de um conhecimento coletivo, conquistado mediante a experiência de gerações inteiras e, por isso, seriam muito mais sábias e instrutivas do que noções constituídas solitariamente.

${ }^{28}$ É claro que podemos facilmente imaginar que a permanência de uma tradição possa ser causada pela imposição de um poder despótico e violento. Em um caso extremo como este, Burke retoma a seus escrúpulos jusnaturalistas: "o poder [...] para ser legítimo deve estar de acordo com essa lei eterna, imutável, em que vontade e razão coincidem” (BURKE, Reflexões sobre a revolução na França, p. 151); “o governo é um artifício da sabedoria humana para prover as vontades humanas. Os homens têm direito a que esses desejos sejam providenciados por esta sabedoria” (BURKE, Reflexões sobre a revolução na França, p. 103), etc. Há ainda inúmeras passagens em que Burke desdenha de qualquer forma de poder político absoluto. Portanto, a permanência que fornece as credenciais morais a uma tradição é aquela que se dá no contexto de um Estado civilizado, com poderes políticos divididos, pautado por princípios racionais, e que satisfaça sua finalidade, que é dar provimento às vontades humanas. Um estado despótico é o contrário de tudo isso. Além disso, não podemos nos esquecer que Burke também sustenta uma teoria sobre os direitos naturais, e que continuam a exercer a função de fornecer critérios de legitimação ou deslegitimação da atuação de um determinado Estado.

${ }^{29}$ BURKE, Reflexões sobre a revolução na França, p. 103. 
Mais uma vez, este aspecto do pensamento político de Schopenhauer apresenta uma forte semelhança com aquele de Burke, quando este considera as tradições como o produto da “sabedoria da espécie", enquanto rejeita o intelectualismo, tão arrogante quanto vazio, dos revolucionários franceses. Uma característica muito forte deste intelectualismo é a sua simplicidade, justamente porque o mesmo abstrai de toda a pluralidade, complexidade e incertezas que são inerentes somente à experiência ${ }^{30}$; no âmbito do a priori, não há espaço para dúvidas ${ }^{31}$ :

Os erros e defeitos de antigas instituições são visíveis e palpáveis. É preciso pouca capacidade para apontá-los [...]. Não há dificuldades no que nunca foi testado. [...] e o entusiasmo ansioso e a esperança enganosa têm todo o vasto campo da imaginação em que podem se estender com pouca ou nenhuma oposição ${ }^{32}$.

Este esquema de pensamento simplório - baseado ora em raciocínios formais destituídos de conteúdo, ora no romantismo da própria imaginação - peca por ignorar a matéria fornecida pela experiência. Uma destas matérias que a mente revolucionária ignora é a própria noção de natureza humana. Burke repreende os projetos filosóficos e políticos dos revolucionários franceses porque nos mesmos não há "uma única referência sequer a ago de natureza moral ou política, nada que esteja relacionado às preocupações, aos atos, às paixões, aos interesses dos homens", e conclui: "hominem non sapiunt" ("não conhecem o homem") 33 .

Mas como abranger tantas informações? Segundo Burke, nem mesmo o conhecimento adquirido por empiria seria suficiente, porque também neste caso ele seria um conhecimento restrito à sabedoria de uma única pessoa, e restrito às experiências de uma única pessoa:

\footnotetext{
30 Talvez isso explique por que pessoas muito jovens, mas já inclinadas às ciências do espírito, geralmente deixam-se levar tão apaixonadamente pelas ideologias.

${ }^{31}$ Isto pode nos levar a crer que o pensamento político de Burke nos conduziria a uma crítica àquele de Kant, tão dedicado a descrições apriorísticas. Optamos por não abordar este possível antagonismo aqui, uma vez que semelhante empreendimento demandaria um trabalho específico e, além disso, é bastante problematizável o papel que a experiência deve exercer na filosofia moral de Kant, para quem, por um lado, o dever enunciado a priori já equivale moralmente ao poder de executá-lo (neste sentido, por exemplo: KANT, Crítica da razão prática, p. 51/A 54); e, por outro, o mesmo Kant reconhece, em pelo menos duas passagens, que a antropologia é indispensável à moral porque contém “as condições de cumprimento" da parte que é de origem a priori no conhecimento moral (KANT, Metaphysik der Sitten, p. 322/AB 11), e que "a Moral precisa da Antropologia para sua aplicação aos homens” (KANT, Fundamentação da metafísica dos costumes, p.181/Ak 412). Uma teoria moral composta por uma parte imutável (seja ela transcendente ou transcendental) e pelas condições empíricas de aplicabilidade daquela, não pode ser tão divergente, em essência, daquilo que pretende Burke.

32 BURKE, Reflexões sobre a revolução na França, p. 249-250.

${ }^{33}$ BURKE, Reflexões sobre a revolução na França, p. 269.
} 
Estamos receosos de colocar homens para viver e negociar cada um pelo seu próprio estoque privado de razão, porque nós suspeitamos que este estoque em cada homem é pequeno, e que os indivíduos fariam melhor em se valer do banco e do capital gerais das nações e das $\operatorname{eras}^{34}$.

Acima do "estoque privado de razão”, está o “capital geral das nações”. Com base nisso, deduz Kirk que

O indivíduo é tolo, mas a espécie é sábia; preconceitos [prejudices] e prescrições [prescriptions] e presunções são os instrumentos que a sabedoria da espécie utiliza para preservar o homem contra suas próprias paixões e apetites ${ }^{35}$.

Por "preconceito" (prejudice), neste contexto, devemos entender não o sentido vulgar que a palavra normalmente assume, mas um "conhecimento meio-intuitivo que possibilita ao homem compreender os problemas da vida sem decomposição lógica"36; em outro trecho, Kirk define-os simplesmente como "as exigências da consciência" ${ }^{37}$. Portanto, não se trata de uma defesa da ignorância, mas apenas se está afirmando que nossas percepções morais mais profundas e imediatas não precisam ser constituídas a partir de uma longa cadeia de raciocínios para que sejam legítimas. Kant (1956, p. 321/AB II), por exemplo, era da mesma opinião: "todo homem tem em si [uma metafísica dos costumes], embora comumente apenas de um modo obscuro" ${ }^{38}$. Também Schopenhauer sustentava a mesma convicção quanto à legitimidade das intuições morais comuns. Por este motivo, ele restringiu a filosofia ao âmbito puramente teórico: "toda filosofia é sempre teórica, já que lhe é essencial manter uma atitude puramente contemplativa [...], e sempre inquirir, em vez de prescrever regras” (W I, §53, p. 353). Isso significa que a capacidade de distinguir entre o moralmente certo e o moralmente errado não depende de longas e exaustivas elaborações discursivas e de prescrições de Ética filosófica. No âmbito moral, a filosofia se restringe ao esclarecimento teórico de nossos sentimentos ou intuições, e ao apontamento de seus fundamentos implícitos. No mesmo sentido se expressou Burke:

Pensamos que não há descobertas a serem feitas na moral, nem em muitos dos grandes princípios do governo, nem nas ideias de liberdade, que foram compreendidas muito antes de termos nascido, tão bem quanto serão após o bolor estar acumulado sobre nossa presunção e o túmulo silencioso tiver imposto sua lei à nossa petulante loquacidade ${ }^{39}$.

\footnotetext{
${ }^{34}$ BURKE, Reflexões sobre a revolução na França, p. 140.

${ }^{35} \mathrm{KIRK}$, The conservative mind, p. 37-38.

${ }^{36}$ KIRK, The conservative mind, p. 42.

${ }^{37}$ KIRK, The conservative mind, p. 41.

${ }^{38}$ KANT, Metaphysik der Sitten, p. 321/AB II.

${ }^{39}$ BURKE, Reflexões sobre a revolução na França, p. 139.
} 
Todos aqueles elementos normativos - preconceitos, o direito tradicional, as presunções morais - são registros e produtos do acúmulo daquela sabedoria da espécie, chamada por Schopenhauer de "sabedoria da própria vida". Em suma, a vantagem dos usos e costumes sobre as idealizações jurídicas da razão pura consiste no fato de que aqueles são o resultado de inúmeras experiências individuais, enquanto que as idealizações são o resultado de uma ou de algumas mentes individuais. Além disso, usos e costumes possuem mais conteúdo, porque foram definidos gradualmente de acordo com particularidades e circunstâncias vivenciadas por várias gerações. A razão pura, por definição, é completamente ignorante a este conteúdo; sua sabedoria é formal - e isso significa que, estritamente falando, a razão pura não possui sabedoria alguma, se considerarmos que "sabedoria" se refere ao saber extraído a partir da experiência. Portanto, o direito idealizado pela razão pura possui uma universalidade formal, enquanto que o direito tradicional é dotado de uma universalidade material, ou, dizendo mais propriamente, de uma generalidade material, pois, conforme já explicado, ele nunca é perfeito no sentido de estar completamente acabado, mas é obra de uma contínua, gradual e inconclusa experiência social.

\section{Considerações finais}

A partir do exposto, é de se perguntar: o pensamento político maduro de Schopenhauer contém alguma originalidade? Aparentemente, não. Note-se: aparentemente. Pois de fato Schopenhauer, em seu pensamento político tardio, não parece ter acrescentado grande coisa ao pensamento político de Burke, ao menos em suas conclusões. A crítica ao direito abstrato, a definição do conhecimento prático-político como mediação da vigência e efetividade do direito natural, a exigência de adaptar o direito puro às exigências das circunstâncias (conforme a analogia das substâncias químicas), a rejeição ao intelectualismo político em benefício das tradições, a referência a uma "sabedoria da própria vida" gradualmente amadurecida pela experiência conjunta de uma nação... Todas estas teses de filosofia política já parecem ter sido antecipadas nas Reflexões de Burke, de modo que, após bem compreendidas, tem-se a impressão de que o $\S 127$ de Parerga e Paralipomena não fez muito mais do que oferecer um resumo das teorias políticas de Edmund Burke.

Mas não devemos nos esquecer de que Burke censurou nos revolucionários franceses a ausência de uma antropologia definida. Porém, o próprio Burke careceu de uma antropologia deste tipo, ao menos nas Reflexões. E é nisto que acreditamos residir a força de Schopenhauer enquanto filósofo político: sua metafísica fundamenta, com enorme rigor e brilho, uma antropologia pessimista, da qual aquelas conclusões políticas tanto dependem para que façam sentido. Pois apesar de Burke rejeitar textualmente qualquer 
antropologia pessimista ao dizer que "os casos de eminente depravação devem ser tão raros quanto os de bondade transcendente" 40 , o fato é que, conceitualmente, é justamente este pessimismo que fornece a base filosófica necessária para uma filosofia política que voltou-se violentamente contra o entusiasmo revolucionário, com sua fé no poder ilimitado da razão e na capacidade humana de sempre autodefinir-se e de controlar seu destino, bem como no êxito de projetos políticos jamais testados pela experiência social e histórica de um povo. Em tudo isso deixa-se transparecer ceticismo e falta de fé no caráter moral do homem e na sua faculdade de conhecimento abstrato.

Consequentemente, este pessimismo, que em Burke é apenas expressão de temperamento, em Schopenhauer assume justificação filosófica, na medida em que o mesmo, por meio de sua conhecida tese metafísica, concebe como centro e essência do ser humano a vontade, este imutável ímpeto de vida e poder que se utiliza da razão, sem a ela subordinar-se.

\section{Referências}

ARENDT, Hannah. Origens do totalitarismo. Tradução de Roberto Raposo. São Paulo: Companhia das Letras, 2012.

ARISTÓtElES. A política. Tradução de Nestor Silveira Chaves. Rio de Janeiro: Nova Fronteira, 2011.

ARISTÓteles. Ética a Nicômaco. Tradução de António de Castro Caeiro. São Paulo: Atlas, 2009.

BIRNBACHER, Dieter; KÜPPER, Georg. Schopenhauer und die Wert der Freiheit. In: INGEKAMP, Heinz Gerd; BIRNBACHER, Dieter; BAUMANN, Lutz. SchopenhauerJahrbuch 75(1994). Würzburg: Königshausen \& Neumann, 1993. pp. 75-96.

BURKE, Edmund. Reflexões sobre a revolução na França. Tradução de Marcelo Gonzaga de Oliveira e Giovanna Libralon. Campinas, SP: Vide Editorial, 2017.

HOBBES, Thomas. Leviathan. Londres: Penguin Books, 1985.

HUSSERL, Edmund. A crise das ciências europeias e a fenomenologia transcendental. Tradução de Diogo Falcão Ferrer. Rio de Janeiro: Forense Universitária, 2012.

KANT, Immanuel. Crítica da razão prática. Tradução, introdução e notas de Valerio Rohden. São Paulo: Martins Fontes, 2011.

KANT, Immanuel. Fundamentação da metafísica dos costumes. Tradução, introdução e notas de Guido Antônio de Almeida. São Paulo: Discurso Editorial e Barcarolla, 2009.

${ }^{40}$ BURKE, Reflexões sobre a revolução na França, p. 221. 
KANT, Immanuel. Metaphysik der Sitten, Rechtslehre. In: Werke in sechs bänden: schriften zur ethik und religionsphilosophie. Wiesbaden: Insel Verlag, 1956.

KELSEN, Hans. Teoria pura do direito. Tradução de João Baptista Machado. São Paulo: Martins Fontes, 2006.

KIRK, Russell. The conservative mind: from Burke to Eliot. Sétima edição revisada. Washington, D.C.: Regnery Publishing, 2001.

McAllister, Ted. Revolta contra a modernidade. Tradução de Túlio Sousa Borges de Oliveira. São Paulo: É Realizações, 2017.

MOREIRA, Ivone. A filosofia política de Edmund Burke. São Paulo: É Realizações, 2019.

MÜNKLER, Herfried. Ein janusköpfiger Konservatismus: Arthur Schopenhauers politische Idee. In: SPIERLING, Volker. Schopenhauer im Denken der Gegenwart. 23 Beiträge zu seiner Aktualität. München: Piper, 1987. pp. 217-237.

RAMOS, Cesar Augusto. Aristóteles e o sentido político da comunidade ante o liberalismo. In: Kriterion, Belo Horizonte, n 129, Jun./2014, p. 61-77

RAMOS, Flamarion Caldeira. Pessimismo e política: conservadorismo e crítica social em Schopenhauer. In: Voluntas: Revista Internacional de Filosofia, Santa Maria - Vol. 9, n. 2, jul.-dez. 2018, p. 35-53.

SCHOPENHAUER, Arthur. Die Welt als Wille und Vorstellung, zweiter Band. Ed. de Arthur Hübscher. Zürich: Diogenes, 1977.

SCHOPENHAUER, Arthur. O mundo como vontade e como representação, $1^{0}$ tomo. Tradução de Jair Barboza. São Paulo: UNESP, 2005.

SCHOPENHAUER, Arthur. Parerga und Paralipomena. zweiter Band. Ed. de Arthur Hübscher. Zürich: Diogenes, 1977.

SCHOPENHAUER, Arthur. Sobre o fundamento da moral. Tradução de Maria Lúcia Mello Oliveira Cacciola. São Paulo: Martins Fontes, 2001. 